\title{
GENETIC DIVERSITY AMONG ASPARAGUS SPECIES USING MORPHOLOGICAL CHARACTERISTICS AND RAPD MARKERS IN PAKISTAN
}

\author{
Irshad. M., M. Idrees ${ }^{1,2}$, A. Tariq ${ }^{1,2}$, M. L. Pathak ${ }^{1,2}$, M. Hanif ${ }^{3}$ and R. Naeem \\ Department of Biotechnology and Genetic Engineering, Kohat university of Science and Technology \\ (KUST). Kohat, Pakistan; ${ }^{1}$ CAS Key Laboratory of Mountain Ecological Restoration and Bioresource \\ Utilization \& Ecological Restoration and Biodiversity Conservation Key Laboratory of Sichuan \\ Province, Chengdu Institute of Biology, Chinese Academy of Science, P.O Box 416, Chengdu 61004, \\ China; ${ }^{2}$ The University of Chinese Academy of Science, Beijing, China; ${ }^{3}$ Department of Genetics, \\ Hazara University, Mansehra, Pakistan.
}

\begin{abstract}
The aim of present research was to study the genetic diversity among Asparagus species and its cultivars using morphological characteristics and RAPD markers. In-vitro and field experiments of 14 germplasm sources of Asparagus species and its cultivars were conducted at the Kohat University of Science and Technology to estimate the comparative performance. Highest genotypic variance, phenotypic variance, genotypic and phenotypic coefficient of variance were observed in shoot height in shoot related traits were 318.40, 320.30, 939.34 and 944.96, respectively, whereas highest values for root related traits were observed in root length that were 21.84, 22.35, 141.60 and 144.91 respectively. Among the shoot related traits maximum heritability, genetic advance and genetic gain were calculated for shoot length, while in root related traits these characters were highest for root dry weight. RAPD markers were used to evaluate genetic diversity analysis of 14 germplasm sources of Asparagus species and its cultivars. RAPD markers generated a total of 247 bands, of these 239 bands were polymorphic with average of 34.1 bands per primer. Cluster analysis based on Neighbor Joining methods showed that wild species (A. adsendens, A. densiflorus, A. capitatus, A. gracelus, A. plumosus, A. racemosus and A. setaceus) were genetically distant from A. officinalis and its cultivars (Abril, Apollo, Gersengum, Huchel, Para seletion and Taranga). The results of the present investigations could be particularly used for authentic identification and would be useful for evaluation of genetic improvement of Asparagus species and its cultivars.
\end{abstract}

Key words: Seed sources; Asparagus officinalis; Genetic advance; Heritability; RAPD; Genetic diversity.

\section{INTRODUCTION}

Asparagus Linnaeus (1753) belongs to the family Aspargaceae, which are extensively distributed all over the world. The natural habitats of Asparagus are tropical and sub-tropical regions. It is a perennial, herbaceous plant having a height of 100-150 cm. The roots of Asparagus are moist tuberous extending up to $30-100 \mathrm{~cm}$ and up to $2 \mathrm{~cm}$ in thickness. The roots are arranged in cluster form, attached at the base of the stem. The stem is fat having many soft branches. The leaves are needle like having a length of 6$12 \mathrm{~mm}$ and width of $1 \mathrm{~mm}$, arrange in clusters. Flowers are greenish-white to yellowish, and round in shape. The fruits are small red berry, 6-10 $\mathrm{mm}$ in diameter and are poisonous to human (Chen et al. 2000).

Asparagus prefers different types of soil for their growth including wobbly soil which is suitable for its profound growth. Naturally Asparagus is grown in slightly alkaline soils (Thompson and Kelly 1957). Many species of Asparagus are valued vegetable crops; whereas A. adscendens, A. capitatus and A. racemosus are widely used for medicinal purposes. A. densiflorus, A. setaceus and A. plumosus have economic importance for both horticultural and ornamental purposes. A. adscendens are specifically confined to Kashmir regions of Pakistan and considered as important medicinal plants that can be used for various medical purposes including antifungal, anti-inflammatory, anti-mutagenic, diuretic and as anti-cancer drug. Roots of Asparagus are found to possess antioxidant, anti-ADH activity, anticancer 
activity, anti-ulcerogenic activity, anti-inflammatory activity and antimicrobial activity (Mandal et al. 2000). It has been also used for cleaning, strengthening and nourishing female reproductive system. It is also used for premenstrual syndrome (PMS) and also for sexual weakness (Frawley 1989). The main active components of the roots of Asparagus are saponins and steroidal, while Asparagine, Arginine, Tyrosine, Flavonoids (kaempferol, quercetin and rutin), Tannin and Resin are other primary chemical constituents (Negi et al. 2010).

Conventionally, evaluation and characterization of genetic diversity are based on the variation in quantitative and qualitative traits. The evaluation of agro-morphological traits does not usually require complex experiments and advance instruments. Therefore, experiments for these traits are relatively inexpensive, rapid and simple to analyze. For this reason, to evaluate genetic variation morphological parameters are important (van Beuningen and Busch 1997).

RAPD is based on the amplification of genomic DNA with single primers of arbitrary nucleotide sequence (Williams et al. 1990). RAPD primers identify polymorphism in the absence of definite nucleotide sequence information. It is not possible to differentiate the amplified DNA fragment whether it is homozygous (two identical copies) or heterozygous (two different copies) at exact locus because RAPD markers are mostly dominant. In recent years, fingerprinting systems based on RAPD study have been progressively more utilized for detecting genetic polymorphism in several plant genera. Due to technical simplicity and speed, RAPD methodology has been used for diversity analysis in many medicinal plant species ( $\mathrm{Li}$ et al. 2002). PCR based RAPD markers have been widely used in assessing genetic variation within a species by measuring genetic diversity in many species, including medicinal plants.

\section{MATERIAL AND METHODS}

Germplasm and leaf samples of Asparagus species were collected from different regions of Pakistan including Islamabad, Lahore, Kohat and Swat as indicated in flora of Pakistan. The samples were collected and immediately stored. Sampling areas and geographical description are presented in Table 1.

Table 1. Collection sites and environmental parameters for Asparagus species and cultivars.

\begin{tabular}{llllll}
\hline Species \& Cultivars & Type & Collecting sites & Altitude & Latitude & Longitude \\
\hline Asparagus officinalus & Vegetative & NARC, Islamabad & $490 \mathrm{~m}$ & $33^{\circ} 43^{\prime} \mathrm{N}$ & $73^{\circ} 04^{\prime} \mathrm{E}$ \\
A. officinalus C.V. Abril & CV & ARI, Mingora & $984 \mathrm{~m}$ & $34^{\circ} 78^{\prime} \mathrm{N}$ & $72^{\circ} 36^{\prime} \mathrm{E}$ \\
A. officinalus C.V. Appollo & $\mathrm{CV}$ & ARI, Mingora & $984 \mathrm{~m}$ & $34^{\circ} 78^{\prime} \mathrm{N}$ & $72^{\circ} 36^{\prime} \mathrm{E}$ \\
A. officinalus C.V. Gersengum & $\mathrm{CV}$ & ARI, Mingora & $984 \mathrm{~m}$ & $34^{\circ} 78^{\prime} \mathrm{N}$ & $72^{\circ} 36^{\prime} \mathrm{E}$ \\
A. officinalus C.V. Huchel & $\mathrm{CV}$ & ARI, Mingora & $984 \mathrm{~m}$ & $34^{\circ} 78^{\prime} \mathrm{N}$ & $72^{\circ} 36^{\prime} \mathrm{E}$ \\
A. officinalus C.V. Para selection & $\mathrm{CV}$ & ARI, Mingora & $984 \mathrm{~m}$ & $34^{\circ} 78^{\prime} \mathrm{N}$ & $72^{\circ} 36^{\prime} \mathrm{E}$ \\
A. officinalus C.V. Taranga & $\mathrm{CV}$ & ARI, Mingora & $984 \mathrm{~m}$ & $34^{\circ} 78^{\prime} \mathrm{N}$ & $72^{\circ} 36^{\prime} \mathrm{E}$ \\
A. adsendens & Medicinal & Jerma, (Kohat) & $489 \mathrm{~m}$ & $33^{\circ} 58^{\prime} \mathrm{N}$ & $71^{\circ} 43^{\prime} \mathrm{E}$ \\
A. capitatus & Medicinal & Ghalegay (Swat) & $950 \mathrm{~m}$ & $34^{\circ} 69^{\prime} \mathrm{N}$ & $72^{\circ} 26^{\prime} \mathrm{E}$ \\
A. gracelus & Medicinal & Shamozu (Swat) & $974 \mathrm{~m}$ & $34^{\circ} 51^{\prime} \mathrm{N}$ & $72^{\circ} 25^{\prime} \mathrm{E}$ \\
A. densiflorus & Arnamental & More green Nursery (Lahore) & $217 \mathrm{~m}$ & $31^{\circ} 34^{\prime} \mathrm{N}$ & $74^{\circ} 22^{\prime} \mathrm{E}$ \\
A. plumosus & Medicinal & Mingora (Swat) & $950 \mathrm{~m}$ & $34^{\circ} 69^{\prime} \mathrm{N}$ & $72^{\circ} 26^{\prime} \mathrm{E}$ \\
A. racemosus & Medicinal & Charbhage (Swat) & $1032 \mathrm{~m}$ & $34^{\circ} 83^{\prime} \mathrm{N}$ & $72^{\circ} 44^{\prime} \mathrm{E}$ \\
A. setaceus & Arnamental & Bhage Jinnah (Lahore) & $209 \mathrm{~m}$ & $31^{\circ} 54^{\prime} \mathrm{N}$ & $74^{\circ} 33^{\prime} \mathrm{E}$ \\
\hline
\end{tabular}

\section{Germination of Asparagus}

Germplasm of Asparagus species was sterilized by treating with 3\% sodium hypochlorite and then washed three times with sterile water. One percent Agar medium was prepared by adding one gm Agar into $100 \mathrm{ml}$ distilled water and sterilized for 20 minutes at $120^{\circ} \mathrm{C}$. Agar medium was cooled up to $50^{\circ} \mathrm{C}$ and poured around $20 \mathrm{ml}$ medium into Petri dishes. After solidification of the medium, healthy seeds that sank in the water were selected and inoculated for germination under sterilized condition by placing 
them at $25^{\circ} \mathrm{C} \pm 2{ }^{\circ} \mathrm{C}$ in a growth chamber. The swollen seeds with green embryos were observed after 12 days of incubation and were considered as germinated (Hailes and Seaton 1989).

\section{Morphological traits}

The field trial was established each with ten replications and ten seeds in a plot for evaluation of the Asparagus growth performance. The optimum seed to seed distance was $5 \mathrm{~cm}$ and row to row distance was $10 \mathrm{~cm}$ in order to achieve the full coverage of the soil which minimized the competition with weeds and assured best performance. The germination of germplasm was started after twenty days. Plants were harvested at the age of two and half months, and growth performance data for nine different morphological traits of the seedlings were recorded that included number of shoot, shoot height, shoot weight (wet and dry), number of roots, root length, root diameter and root weight (wet and dry) for each plant.

\section{RAPD Primers and RAPD PCR amplification}

A total of seven RAPD primers (Operon Technologies, Alameda, CA, USA) was used for PCR amplification of DNA template of Asparagus species and A. officinalis cultivars. 7 RAPD primers including (RPI 4, RPI 5, TIBM BA-04, TIBM BA-14, TIBM BB-12, TIBM BB-13, and TIBM BD-19) are illustrated in Table 2.

The PCR reaction mixture with a total volume of $25 \mu 1$ containing $0.5 \mu 1$ of assay buffer, $0.2 \mathrm{mM}$ dNTPs, , 1U of Taq DNA polymerase, $1.5 \mathrm{mM}$ of $\mathrm{MgCl}_{2}, 0.2$ pico moles of primers, $50 \mathrm{ng}$ of template DNA. DNA amplification was performed with arbitrary Polymerase Chain Reaction (PCR) in an ABI thermal cycler (Applied Biosystem Inc, USA). Each of the 35 PCR thermal Cycles standardized for this study, consisted of denaturation of DNA at $94{ }^{\circ} \mathrm{C}$ for 45 seconds, primer annealing at $37{ }^{0} \mathrm{C}$ for 1 minute and primer extension at $72{ }^{\circ} \mathrm{C}$. All PCR samples were subjected to an initial denaturation at $94{ }^{\circ} \mathrm{C}$ for 5 minutes and final extension at $72{ }^{\circ} \mathrm{C}$ for 10 minutes followed by hold temperature at $4{ }^{0} \mathrm{C}$. Amplified PCR products were size-separated by carrying out electrophoresis on $1.5 \%$ agarose gels, stained with ethidium bromide in $1 \times \mathrm{TBE}$ buffer for 1 hour at $125 \mathrm{~V}$. Gels with amplified products were visualized and photographed using Gel documentation system.

\section{Data analysis}

The genotypic and phenotypic components and variances for the various traits among Asparagus species were calculated by following the procedure described by Burton (1952). By using the following formula $h^{2}=\sigma^{2} g / \sigma^{2} p$, broad sense heritability $\left(h^{2}\right)$ was estimated where $\sigma^{2} g$ is genotypic variance and $\sigma^{2} \mathrm{p}$ is phenotypic variance (Lush 1949). The genetic advance was calculated as described by Johnson $e t$ al. (1955) for all traits studied. Genetic advance (Gs) was calculated as Gs $=\mathrm{K} \cdot \mathrm{h}^{2} \cdot \sqrt{ } \sigma^{2} \mathrm{p}$, where $\mathrm{K}$ is the

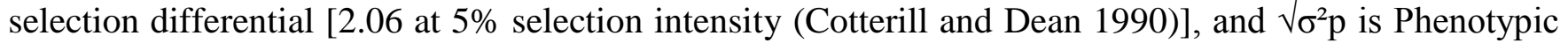
standard deviation. The expected genetic gain, percent of mean was calculated following the procedure of Burton and Devane (1953). Genetic gain was calculated as Genetic gain $=(G s /$ mean $) \times 100$, where $G s=$ Genetic Advance. The correlation among the traits was analyzed to find out the relationship of one trait and its influence on other traits using Mstat $\mathrm{C}$ and statistic 9 software. Unequivocally, scorable and consistently reproducible amplified DNA fragments were transformed into binary matrix $(1=$ presence, $0=$ absence). Data analyses were conducted using only the polymorphic bands. Genetic similarity matrix was generated using Nei genetic similarity coefficient (Nei and Li 1979), the cluster analysis was performed based on Neighbor joining algorithm and dendrogram was constructed by help of NTSYSpc 2.02 software (Rohlf 2000). 
Analysis of the amplified DNA fragments for RAPD bands were scored manually as presence (1) or absence (0) of data. The results were analyzed on the principle that a band is considered to be 'polymorphic' if it is present in some individuals and absent in others and 'monomorphic' if present in all individuals. Numerical Taxonomy System (NT-SYS), version 2.11 from applied biostatis Inc. (2002), was used to analyze the result obtained from scoring. For measuring similarity among Asparagus species and A. officinalis cultivars, Nei and Lie genetic similarity coefficient was used (Nei and Li 1979).

\section{In-vitro seed germination}

\section{RESULTS AND DISCUSSION}

Asparagus species and cultivars were germinated on Agar medium, After nine days of sowing, germination was started in Asparagus species (Fig. 1). After 12 days germination, highest percent germination (100\%) was observed in A. officinilis, A. officinilis Cv. Abril and A. officinilis Cv. Taranga, while lowest percent germination $(33.33 \%)$ was observed in A. capitatus, A. racemosus and A. setaceus (Fig. 2).
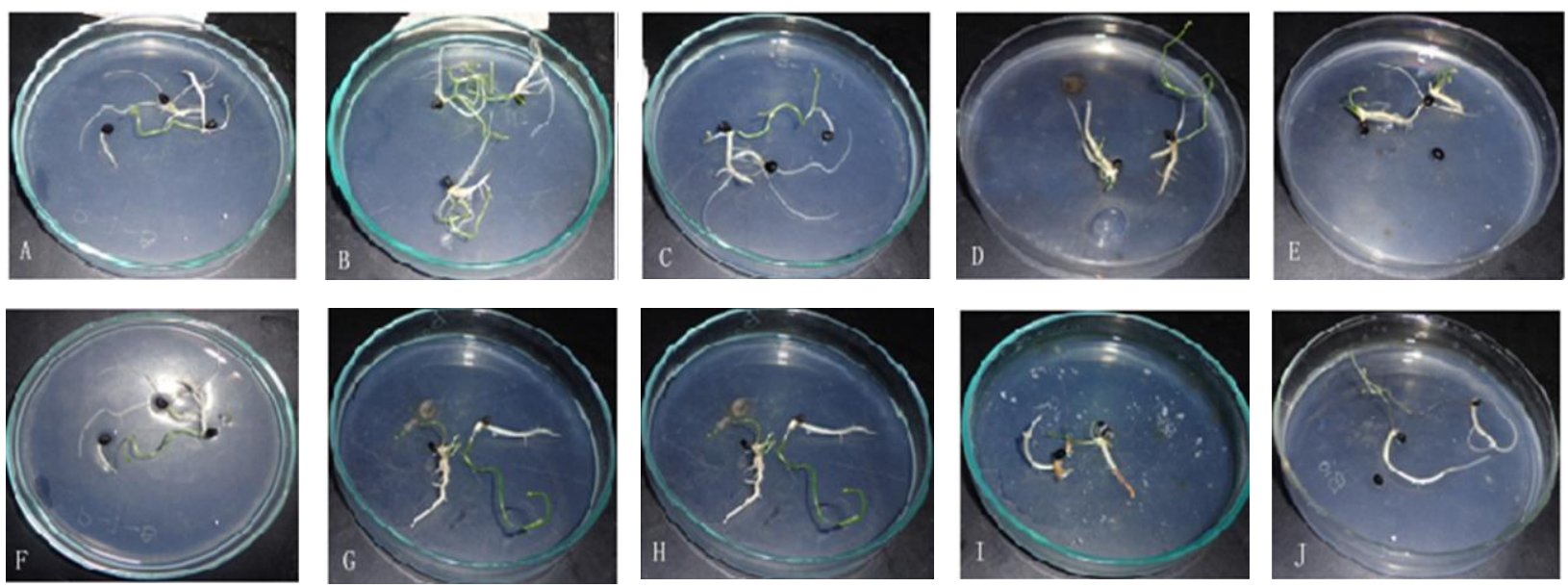

Fig. 1. Asparagus growth in Agar medium: A. A. officinalis; B. A. officinalis cv. Taranga; C. A. officinalis cv. Huchel; D. A. officinalis cv. Gersengum; E. A. officinalis cv. Para; F. A. officinalis cv. Apollo; G. A. officinalis Abril; H. A. racemosus; I. A. adscendens; and $\mathbf{J}$. A. gracilus.

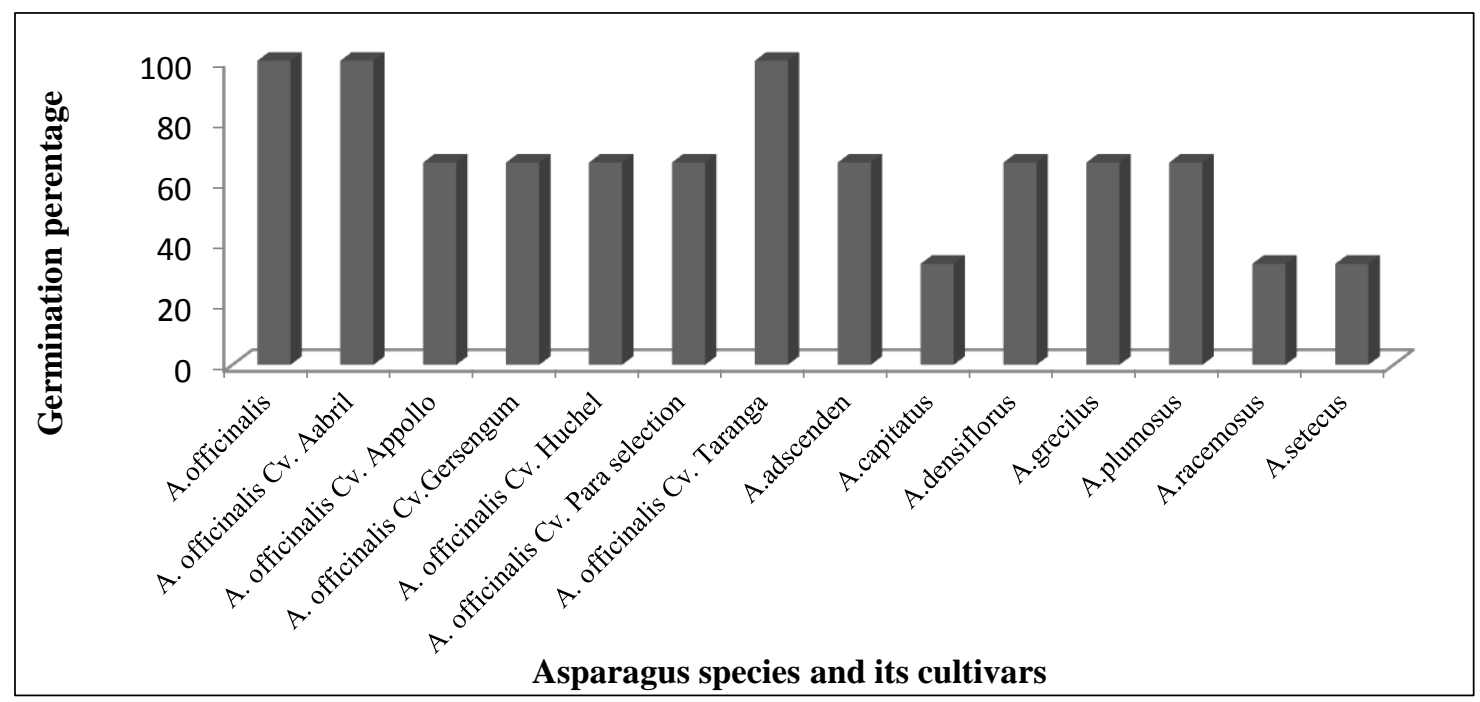

Fig. 2. Percent germination of different Asparagus species. 


\section{Morphological parameters}

For the evaluation of morphological parameters, growth data were collected for Asparagus species and were statistically analyzed using MstatC (Table 2). The maximum coefficient of variation (CV) was observed in root diameter $(74.50 \%)$, whereas minimum coefficient of variation was observed in shoot height $(19.95 \%)$.

Table 2. Morphological parameters studied for different Asparagus species.

\begin{tabular}{lccccccccc}
\hline Static & \multicolumn{4}{c}{ Shoot } & \multicolumn{3}{c}{ Root } & & \\
\cline { 2 - 9 } & Number & Height & $\begin{array}{c}\text { Fresh } \\
\text { weight }\end{array}$ & $\begin{array}{c}\text { Dry } \\
\text { weight }\end{array}$ & Number & Length & Diameter & $\begin{array}{c}\text { Fresh } \\
\text { weight }\end{array}$ & $\begin{array}{c}\text { Dry } \\
\text { weight }\end{array}$ \\
\hline Average & 2.49 & 16.94 & 0.29 & 0.09 & 3.13 & 7.71 & 2.01 & 0.41 & 0.13 \\
Maximum & 6 & 39 & 0.89 & 0.28 & 8 & 15 & 4 & 1.71 & 0.48 \\
Minimum & 1 & 3.3 & 0.04 & 0.01 & 1 & 2.7 & 0.5 & 0.03 & 0.01 \\
SD & 1.06 & 7.87 & 0.21 & 0.07 & 1.39 & 2.51 & 1.02 & 0.35 & 0.11 \\
cv & $35.25 \%$ & $19.95 \%$ & $41.77 \%$ & $49.63 \%$ & $23.62 \%$ & $22.69 \%$ & $74.50 \%$ & $46.95 \%$ & $45.15 \%$ \\
\hline
\end{tabular}

The analysis of variance (ANOVA) showed that most of the traits observed for Asparagus species were found significant at the significance level of 0.005 (Table 3).

Table 3. Analysis of variance for morphological traits of Asparagus species.

\begin{tabular}{lccccc}
\hline Traits & $\begin{array}{c}\text { Degree of } \\
\text { freedom }\end{array}$ & $\begin{array}{c}\text { Sum of } \\
\text { squares }\end{array}$ & $\begin{array}{c}\text { Mean sum } \\
\text { of squares }\end{array}$ & Frequency & P value \\
\hline No. of shoot & 5 & 6.857 & 1.371 & 1.766 & 0.006 \\
Shoot height & 5 & 227.808 & 45.562 & 3.9862 & 0.003 \\
Shoot fresh weight & 5 & 0.643 & 0.129 & 8.6587 & 0.002 \\
Shoot dry weight & 5 & 0.035 & 0.007 & 4.0954 & 0.003 \\
No. of Root & 5 & 15.821 & 3.164 & 5.8745 & 0.001 \\
Root length & 5 & 33.799 & 6.76 & 2.2069 & 0.004 \\
Root diameter & 5 & 14.238 & 2.848 & 1.105 & 0.006 \\
Root fresh weight & 5 & 1.167 & 0.233 & 6.2946 & 0.001 \\
Root dry weight & 5 & 0.104 & 0.021 & 6.69 & 0.003 \\
\hline
\end{tabular}

Components of variance including genotypic variance, phenotypic variance, genotypic coefficient of variance and genotypic coefficient of variance for the different morphological traits of Asparagus species are shown in Table 4.

Table 4. Components of variance for the nine morphological traits of Asparagus species.

\begin{tabular}{lcccc}
\hline Character & $\begin{array}{c}\text { Genotypic } \\
\text { variance }\end{array}$ & $\begin{array}{c}\text { Phenotypic } \\
\text { variance }\end{array}$ & $\begin{array}{c}\text { Genotypic coefficient } \\
\text { variance }\end{array}$ & $\begin{array}{c}\text { Phenotypic coefficient } \\
\text { of variance }\end{array}$ \\
\hline No. of shoots & 2.4605 & 2.69 & 49.21 & 51.8 \\
Shoot height & 318.4 & 320.305 & 939.344 & 944.964 \\
Shoot fresh weight & 0.1485 & 0.151 & 25.428 & 25.856 \\
Shoot dry weight & 0.02 & 0.021 & 12.45 & 12.65 \\
No. of root & 3.085 & 29.679 & 49.276 & 473.954 \\
Root length & 21.846 & 22.357 & 141.6 & 144.91 \\
Root diameter & 5.165 & 5.595 & 119.849 & 129.814 \\
Root fresh weight & 0.485 & 0.492 & 59.25 & 60 \\
Root dry weight & 0.052 & 0.053 & 21.17 & 21.37 \\
\hline
\end{tabular}


The maximum genotypic variance was observed for shoot height (318.4), while the minimum genotypic variance was observed for shoot dry weight (0.02). The maximum phenotypic variance, genotypic coefficient of variance and phenotypic coefficient of variance were observed in shoot height (320.305, 939.344 and 944.964), whereas the minimum values were found in shoot dry weight $(0.021$, 12.45 and 12.65 , respectively). The heritability value ranged from 0.10 to 0.99 (Table 5).

Table 5. Genetic parameters for the nine morphological traits of Asparagus species.

\begin{tabular}{lccc}
\hline Characters & $\begin{array}{l}\text { Heritability } \\
\text { (broad sense) }\end{array}$ & $\begin{array}{c}\text { Genetic } \\
\text { advance }\end{array}$ & Genetic gain \\
\hline No. of shoots & 0.91 & 2.96 & 118.22 \\
Shoot height & 0.99 & 36.54 & 215.59 \\
Shoot fresh weight & 0.98 & 0.78 & 267.36 \\
Shoot dry weight & 0.95 & 0.28 & 334.28 \\
No. of roots & 0.1 & 0.38 & 12.01 \\
Root length & 0.98 & 9.41 & 121.96 \\
Root diameter & 0.92 & 4.32 & 200.55 \\
Root fresh weight & 0.98 & 1.41 & 344.93 \\
Root dry weight & 0.98 & 0.46 & 371.68 \\
\hline
\end{tabular}

The maximum heritability was found for shoot height (0.99) whereas the minimum value was observed in the number of roots (0.10). The genetic advance value ranged from 0.28 to 36.54 . The maximum value was observed for shoot height (36.540) whereas the minimum value was found for shoot dry weight (0.28). In case of genetic gain the value ranged from 12.01 to 317.68 (Table 5). The correlation among nine morphological traits of Asparagus species growth ranged from 0.10 to 0.931 (Table 6). The maximum significant correlation was observed for shoot fresh weight (0.931) and shoot dry weight (0.894) whereas the minimum correlation was found between number of shoots and shoots length (0.10).

Table 6. Correlations among nine morphological traits of Asparagus species.

\begin{tabular}{|l|c|c|c|c|c|c|c|c|}
\hline Traits & $\begin{array}{c}\text { No. of } \\
\text { shoots }\end{array}$ & $\begin{array}{c}\text { Shoots } \\
\text { length }\end{array}$ & $\begin{array}{c}\text { Shoots } \\
\text { fresh weight }\end{array}$ & $\begin{array}{c}\text { Shoots dry } \\
\text { weight }\end{array}$ & $\begin{array}{c}\text { No. of } \\
\text { roots }\end{array}$ & $\begin{array}{c}\text { Roots } \\
\text { diameter }\end{array}$ & $\begin{array}{c}\text { Root } \\
\text { length }\end{array}$ & $\begin{array}{c}\text { Root fresh } \\
\text { weight }\end{array}$ \\
\hline No. of shoots & - & & & & & & & \\
\hline Shoots length & 0.100 & - & & & & & & \\
\hline Shoots fresh weight & 0.590 & 0.526 & - & & & & & \\
\hline Shoots dry weight & 0.631 & 0.545 & 0.894 & - & & & & \\
\hline No. of roots & 0.514 & 0.583 & 0.633 & 0.629 & - & & & \\
\hline Roots diameter & 0.288 & 0.584 & 0.479 & 0.485 & 0.653 & - & & \\
\hline Root length & 0.348 & 0.653 & 0.617 & 0.635 & 0.764 & 0.614 & - & \\
\hline Root fresh weight & 0.325 & 0.711 & 0.645 & 0.666 & 0.768 & 0.656 & 0.852 & - \\
\hline Root dry weight & 0.344 & 0.656 & 0.661 & 0.700 & 0.745 & 0.620 & 0.839 & 0.931 \\
\hline
\end{tabular}

Significant at level of 0.05 .

RAPD analysis

RAPD primers were used for genetic diversity among Asparagus species and its cultivars. The amplification of DNA generated from 7 random oligonucleotide primers with each of the 14 Asparagus species produced a total of 239 polymorphic bands out of 247 produced (Table 7 and Fig. 3 ). 
Table 7. Polymorphism of RAPD markers for Asparagus species and its cultivars.

\begin{tabular}{lcccc}
\hline Primers & Sequences & No of bands & Polymorphic bands & Polymorphism \\
\hline RPl 4 & AATCGCGCTG & 23 & 19 & $82.60 \%$ \\
RPl 5 & AATCGGGCTG & 51 & 47 & $92.15 \%$ \\
TIM BA-04 & TCCTAGGCTC & 26 & 26 & $100 \%$ \\
TIM BA-14 & TTCGGCCGAC & 24 & 24 & $100 \%$ \\
TIM BB-12 & CTTCGGTGTG & 61 & 61 & $100 \%$ \\
TIM BB-13 & TCGGGAGTGG & 41 & 41 & $100 \%$ \\
TIM BD-19 & GGTTCCTCTC & 21 & 21 & $100 \%$ \\
\hline Total & & 247 & 239 & - \\
Average & & 35.3 & 34.1 & 96.4 \\
\hline
\end{tabular}
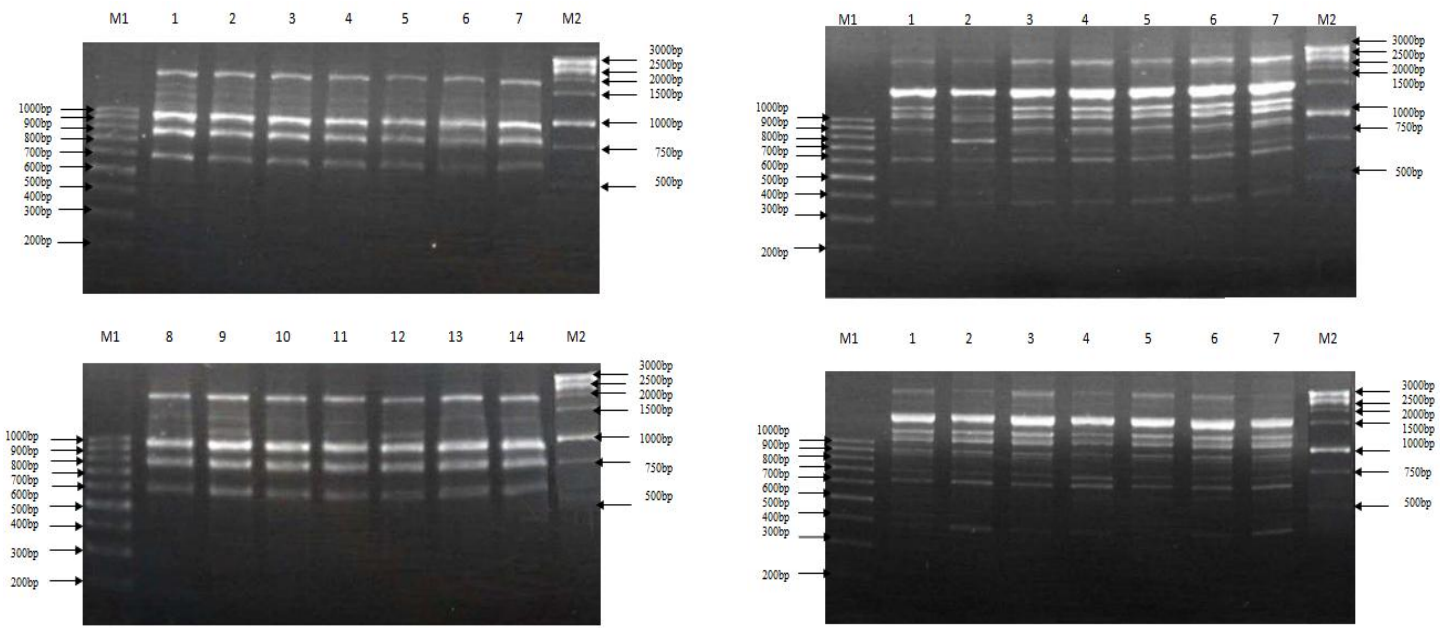

a
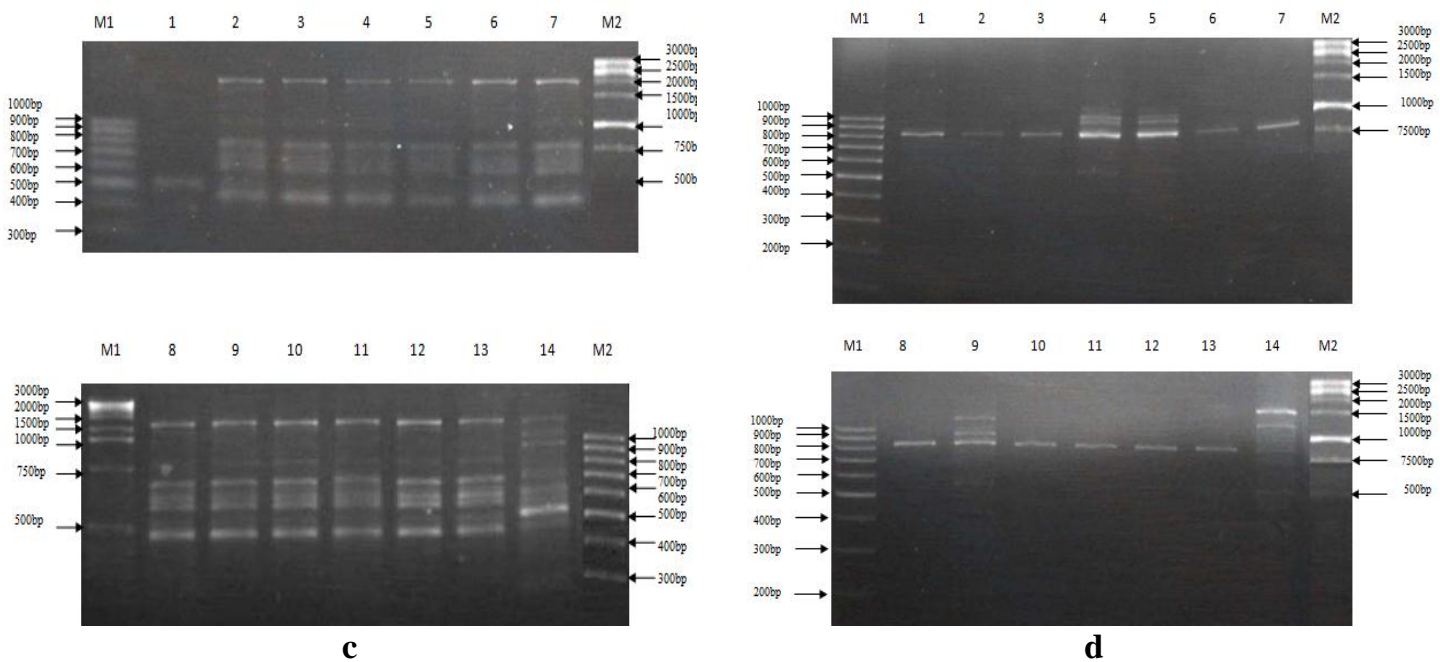

Fig. 3. RAPD pattern generated using primer: a. Rpl4; b. Rpl5; c. TIMBB-13; and d. TIMBB-19: Lane M1 = 100bp marker, Lane M2 = 1kb marker, Lane (1) A. officinalis, (2) A.officinilis Cv. Abril, (3) A. officinilis Cv. Apollo, (4) A. officinilis Cv. Gersengum, (5) A. officinilis Cv. Huchel, (6) A. officinilis Cv. Para, (7) A. officinilis Cv. Taranga, (8) A. adsendens, (9) A. capitatus, (10) A. densiflorus, (11) A. plumosus, (12) A. racemosus, (13) A. setecus, (14) A. gracelis. 
The calculation of genetic similarity coefficient was based on 239 polymorphic bands. The number of bands for each primer ranged from 21 to 61 with an average of 34.1 bands per primer. The similarity matrix obtained from RAPD analysis showed similarity coefficient ranged from 0.54 to 0.97 (Table 8).

Table 8. Genetic similarity indexes of Asparagus species and cultivars using RAPD analysis.

\begin{tabular}{|c|c|c|c|c|c|c|c|c|c|c|c|c|c|c|}
\hline & 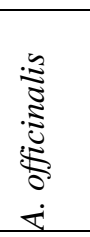 & 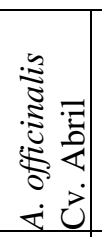 & 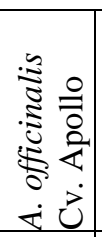 & 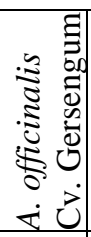 & 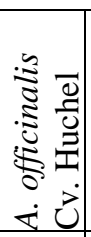 & 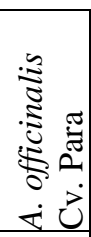 & 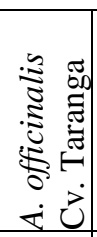 & 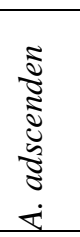 & 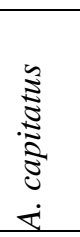 & 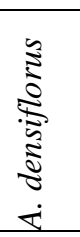 & 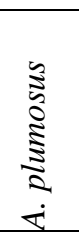 & 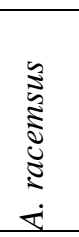 & 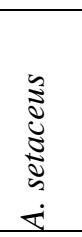 & 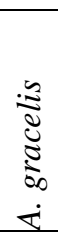 \\
\hline A. officinalis & - & & & & & & & & & & & & & \\
\hline A. officinalis Cv. Abril & 0.69 & - & & & & & & & & & & & & \\
\hline A. officinalis Cv. Apollo & 0.85 & 0.76 & - & & & & & & & & & & & \\
\hline A. officinalis Cv. Gersengum & 0.71 & 0.71 & 0.84 & - & & & & & & & & & & \\
\hline A. officinalis $\mathrm{Cv}$. Huchel & 0.74 & 0.74 & 0.85 & 0.85 & - & & & & & & & & & \\
\hline A. officinalis Cv. Para & 0.71 & 0.71 & 0.85 & 0.92 & 0.82 & - & & & & & & & & \\
\hline A. officinalis $\mathrm{Cv}$. Taranga & 0.79 & 0.74 & 0.94 & 0.86 & 0.86 & 0.90 & - & & & & & & & \\
\hline A. adscenden & 0.66 & 0.71 & 0.75 & 0.69 & 0.76 & 0.73 & 0.81 & - & & & & & & \\
\hline A. capitatus & 0.68 & 0.67 & 0.75 & 0.70 & 0.76 & 0.73 & 0.76 & 0.78 & - & & & & & \\
\hline A. densiflorus & 0.72 & 0.72 & 0.89 & 0.77 & 0.77 & 0.82 & 0.91 & 0.85 & 0.75 & - & & & & \\
\hline A. plumosus & 0.72 & 0.72 & 0.84 & 0.77 & 0.76 & 0.81 & 0.89 & 0.88 & 0.78 & 0.93 & - & & & \\
\hline A. racemsus & 0.75 & 0.75 & 0.91 & 0.80 & 0.76 & 0.80 & 0.89 & 0.82 & 0.77 & 0.97 & 0.91 & - & & \\
\hline A. setaceus & 0.69 & 0.69 & 0.78 & 0.67 & 0.75 & 0.72 & 0.80 & 0.87 & 0.80 & 0.87 & 0.86 & 0.85 & - & \\
\hline A. gracelis & 0.54 & 0.48 & 0.59 & 0.55 & 0.57 & 0.62 & 0.64 & 0.59 & 0.72 & 0.61 & 0.65 & 0.60 & 0.54 & - \\
\hline
\end{tabular}

The highest similarity 0.97 was observed between A. racemosus and A. densiflorus, while lowest similarity (0.54) was observed between A. officinalis and A. gracelis, and also between A. gracelis and A. setaceus. In cluster analysis using neighbour joining algorithm, Asparagus species were divided into two main clusters (Cluster A and Cluster B) (Fig. 4). Cluster A is further divided into two sub cluster including Cluster I and Cluster II. Cluster I consists of A. officinalis, A. officinalis cultivars, namely Apollo, Abril, Gersengum, Para selection, Huchel and Taranga, while Cluster II comprised of $A$. adscenden, A. setaceus, A. plumosus, A. densiflorus, and A. racemosus. Cluster B comprised of A. capitatus and A.gracelis (Fig. 4).

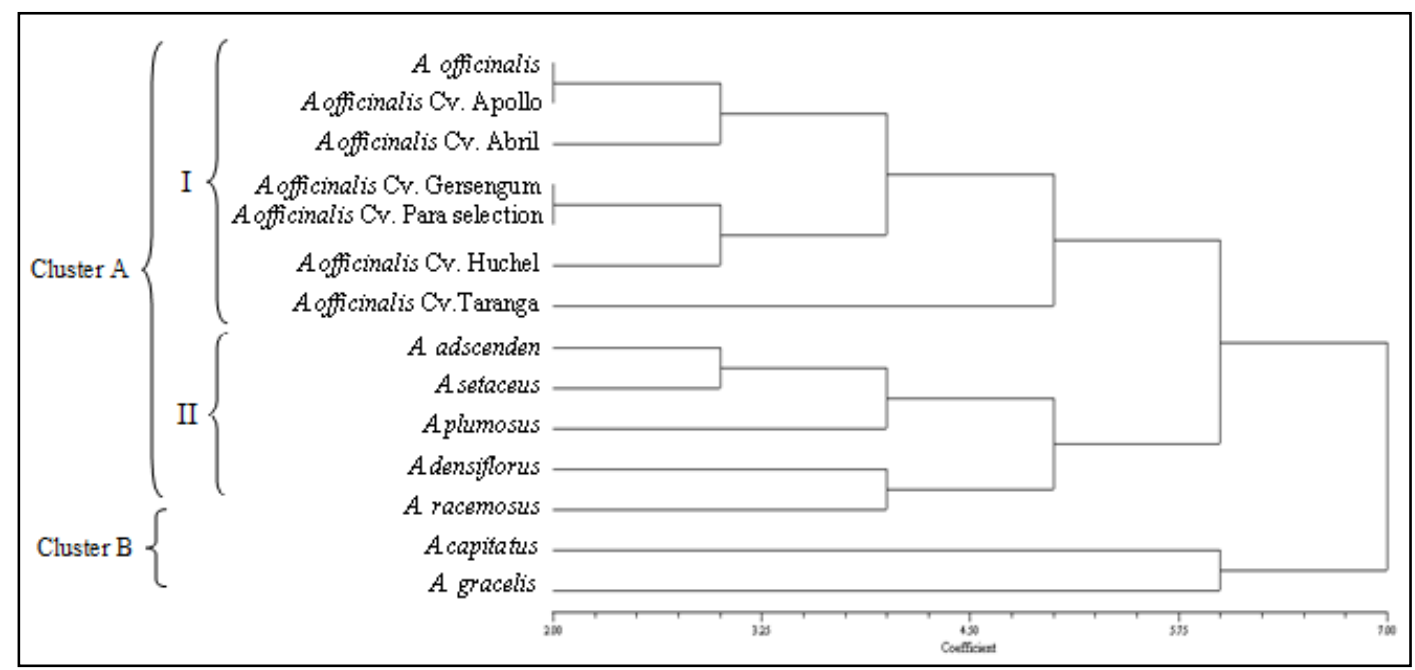

Fig. 4. Phenogram of Asparagus species and its cultivars based on Neighbor joining method using RAPD markers. 
In the present investigation, in vitro germination of Asparagus species and cultivars was found successful by forming healthy seedlings as shown in Fig. 1. Germination test on fresh germplasm showed high germination power. Germination percentage among Asparagus species and its cultivars ranged from 33.33 to $100 \%$. Our results are consistent with the previous works suggested that, Asparagus species show no deep dormancy (Baskin and Baskin 2004, Mario et al. 2005).

The genetic parameters are tremendously significant in predicting the amount of genetic gain to be expected from an improvement program (Kumar et al. 2010). To obtain a considerable amount of genetic gain at a realistic cost while maintaining sufficient genetic variability in the breeding population to ensure future gain is the important objective of plant improvement programs (Zobel and Talbert 1984). The present work analysis showed that morphological parameters could be helpful for biodiversity among Asparagus species. The root related characters showed moderate to high coefficient of variance $(\mathrm{CV})$. In case of heritability, both shoot related and root related characters influenced the vigor of the species which showed high value. In this investigation nine traits including number of shoots, shoot height, fresh shoot weight, dry shoot weight, number of roots, root length, roots diameter, roots fresh weight and dry roots weight were observed. The growth data for the Asparagus species and cultivars showed that mostly cultivars had high values for morphological traits. The most important character was observed in shoot length ranged from $6.0 \mathrm{~cm}$ to $28.67 \mathrm{~cm}$, whereas in A. officinalis cultivars, the values of shoot length were above $20 \mathrm{~cm}$. Another important character observed in $A$. officinalis cultivars was the root length ranged from $3 \mathrm{~cm}$ to $10.58 \mathrm{~cm}$, whereas the shoot length ranged above $7 \mathrm{~cm}$. These investigations showed that cultivars are well adapted to the environment.

Heritability percentage was calculated as a ratio between the genotypic variance and the total phenotypic variance. The value of heritability in broad sense was high for all studied characters ranging from 91 to $99 \%$. High heritability estimates were useful while making selection on the basis of phenotype. For all Asparagus species which showed that assortment process for these characters would definitely bring development in the genotypes. The phenotypic co-efficient of variance was a little higher than genotypic co-efficient of variance for all the traits.

The identification of Asparagus species is more difficult through vegetative characters, although phenotypic expression showed less variation. Besides, morphological and chemical characters cannot determine genetic differentiation and plasticity in population adaptation (Gepts 1993). So they lack the resolving power for individual genotype identification. In the early stages of Asparagus, identification is more difficult. Thus, for the identification of variation among Asparagus species, different molecular techniques have been exploited. For Asparagus species due to the erratic flowering and lack of morphological differences, the recognition of genetic relationship is extremely difficult. Reliable identification of taxa is not only necessary for breeders but also necessary for consumers. Nowadays traditional method of species identification by morphological parameters is gradually being replaced by protein or DNA profiling which is more reliable.

The RAPD techniques are quite sensitive because different DNA profiles were generated by each primer for each of the cultivar and species. Using RAPD techniques, unique DNA profiles were obtained for Asparagus species and cultivars. In present study, 7 random oligonucleotide primers (RPI 4, RPI 5, TIBM BA-04, TIBM BA-14, TIBM BB-12, TIBM BB-13, and TIBM BD-19) were used for genetic characterization of 14 Asparagus species and its cultivars. All these RAPD primers showed good amplifications that were satisfactory and reproducible. The results of the RAPD analysis revealed a total of 239 polymorphic bands with an average of 34.1 bands per primer as shown in Table 7. These results contradict with those of those of Sarabi et al. (2010) and indicate a broad genetic basis of this species in Pakistan; however, consistent with Lal et al. (2011) using 20 RAPD primers, of which 6 primers were reproducible and polymorphic which produced 258 polymorphic bands with an average of 43 bands per 
primer. TIBM BA-04, TIBM BA-14, TIBM BB-12, TIBM BB-13, and TIBM BD-19 primers showed highest number of polymorphism (100\%), while RPI 5 primer showed $92.14 \%$ of polymorphism whereas the lowest number of polymorphism was showed by RPI 4 primer $(82.60 \%)$. The RAPD primers used in the present work produced fragments of different size ranging from 150bp to $3000 \mathrm{bp}$. The minimum (1500 bp) sized fragment was amplified by TIMBB-19 while maximum (3000bp) sized fragment was amplified by primer Rpl 5. Dendrogram constructed on the basis of Neighbor joining algorithm, clustered Asparagus species into two main clusters (Cluster A and Cluster B). Cluster A is subclustered into Cluster I and Cluster II, Cluster I included only A. officinalis and its cultivars while Cluster II comprised of 5 wild Asparagus species. Cluster B made of A. capitatus and A. gracelis were clustered far from the other, suggesting that these may be due to mutation and genetic change or in their genetic background. The clarity of the differentiation of wild species by RAPD in the present work was in consistent with work of Lal et al. (2011), where they clustered Asparagus species on the basis of their geographical isolation.

It was concluded that comprehensive morphological study is advantageous in order to understand all aspects of this variation. RAPD markers for evaluated diversity analysis was highly reproducible, revealed sufficient genetic diversity and a high level of genetic polymorphism. These would be further useful for evaluation of genetic improvement of Asparagus species and its cultivars. Furthermore, we suggest that, RAPD method is convenient for a better understanding of the distribution of genetic variation at intra-specific level as well as for effective conservation.

\section{ACKNOWLEDGEMENTS}

We are grateful to Dr. Maryam Shinwari (Quaid-E-Azam University) and Dr. Maazullah (Agriculture Research Institute) for the facilities provided during sampling of Asparagus species and cultivars. We are also grateful to the reviewers for their helpful comments on the manuscript. Authors are also grateful to Department of Biotechnology and Genetic Engineering, Kohat University of Science and Technology for Instrumental and chemical facilities.

\section{REFERENCES}

Baskin, J. M. and C. C. Baskin. 2004. A classification system for seed dormancy. Seed Sci. Res. 14: 1-16.

Burton, G. W. 1952. Quantitative inheritance in grass. Proc. 6th Int. Grassland Congress (Part I). State College, Pa, Washington D.C., USA, pp. 277-283.

Burton, G. W. and E. H. Devane. 1953. Estimating heritability in tall fecue (Festuca arundinaceae) from replicated clonal material. Agron. J. 45: 478-481.

Chen, X., L. Songyun, X. Jiemei and M. N. Tamura. 2000. Liliaceae. In: Flora of China. 24: 73-263.

Cotterill, P. P. and C. A. Dean. 1990. Successful tree breeding with index selection. CSIRO, Melbourn. 79 pp.

Frawley, Z. 1989. Ayurvedic Healing: A Comprehensive Guide. Passage Press, Salt Lake City, UT, pp. 200-211.

Gepts, P. 1993. The use of molecular and biochemical Markers in crop evolution studies. In: M. K. Hecht (ed.). Evolutionary Biology. Plenum press, New York. 27: 51-94.

Hailes, N. S. J. and P. T. Seaton. 1989. The effects of composition of the atmosphere on the growth of seedlings of Cattleya aurantica. In: H. W. Pritchard (ed.). Modern methods in orchid conservation: the role of physiology, ecology and management. Cambridge University., pp. 73-85. 
Johnson, H. K., H. F. Rabinson and R. E. Comstock. 1955. Estimates of genetic and environmental variability in soybeans. Agro. J. 47: 314-318.

Kumar A, R. Luna, K. Parveen and V. Kumar. 2010. Variability in growth characteristics for different genotypes of Eucalyptus tereticornis Sm. J. Forestry Res. 21(4): 487-491.

Lal, S., N. M. Kinnari, B. V. Parth, D. S. Smit and A. T. Riddhi. 2011. Genetic diversity among five economically important species of Asparagus collected from central Gujarat (India) utilizing RAPD markers (random amplification of polymorphic DNA). Int. J. Adv. Biotech. Res. 2(4): 414-421.

Li, Q., Z. Xu and T. He. 2002. Ex-situ genetic conservation of endangered Vatica guangxiensis (Dipterocarpaceae). China Biol. Conserv. 106: 151-156.

Linnaeus, C. 1753. Description of Asparagus (Aparagaceae). Sp. Pl. 1: 313.

Lush. I. L. 1949. Heritability of quantitative characters in farm animals. Heriditas, Lund, Suppl., pp. 356-387.

Mandal, S. C., A. Nandy, M. Pal and B. P. Saha. 2000. Evaluation of antimicrobial activity of Asparagus racemosus Willd. Phytother Res. 14(2): 118-119.

Mario, L. C. B., C. F. S. D. Denise, A. S. D. Luiz and F. A. Eduardo. 2005. Germination and vigour of primed Asparagus seeds. Sci. Agri. 62(4): 319-324.

Negi, J. S., P. Singh, G. P. Joshi, M. S. Rawat and V. K. Bisht 2010. Chemical constituents of Asparagus. Pharmacogn Rev. 4: 215-220.

Nei, M. and W. Li. 1979. Mathematical model for studying genetic variation in terms of restriction endonucleasis. Proc. Natl. Acad. Sci. 76: 5269-5273.

Rohlf, F. J. 2000. NTSYS-pc: Numerical Taxonomy and Multivariate Analysis System. Version 2. 1. New York: Exeter Software.

Sarabi, B., M. R. Hassandokht, M. E. Hassani, T. R. Masoumi and T. Rich. 2010. Evaluation of genetic diversity among some Iranian wild asparagus populations using morphological characteristics and RAPD markers. Scientia Horticulturae. 126: 1-7.

Thompson, H. C. and W. C. Kelly. 1957. Vegetable Crops. McGraw Hill Book Company Inc., New York. 611 pp.

van Beuningen, L. T. and R. H. Busch. 1997. Genetic Diversity among North American Spring Wheat Cultivars: I. Analysis of the Coeffecient of Parentage Matrix. Crop Sci. 37(2): 570-579.

Williams, J. G. K., A. R. Kubelik, K. J. Livak, J. A. Rofalski and S. V. Tingey. 1990. DNA polymorphisms ampli-fied by arbitrary primers are useful as genetic markers. Nucl. Acids Res. 18: 6531-6535.

Zobel, B. and J. Talbert. 1984. Applied forest tree improvement. John Wiley and Sons. New York. 505 pp. 
